\title{
The Prevalence and Characteristics of Clinicians Who Provide Care in Assisted Living Facilities, 2014-2017
}

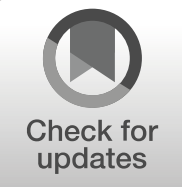

J Gen Intern Med 36(8):2514-6

DOI: $10.1007 / \mathrm{s} 11606-020-06163-9$

(c) Society of General Internal Medicine 2020

\section{INTRODUCTION}

Over 800,000 individuals reside in 28,900 assisted living facilities (ALFs) nationwide. ${ }^{1}$ ALF residents tend to be medically complex and increasingly depend on services provided in ALFs. ALF residents require assistance with 1.9 activities of daily living on average, over half are age 85 or older, and $71 \%$ have some degree of cognitive impairment. $^{2}$ Little is known about the clinicians who provide care in ALFs. We estimated the prevalence and identified the characteristics of clinicians who provide care in ALFs, including both physicians and advanced practitioners (APs).

\section{METHODS}

Part B claims from 2014 through 2017 for a 20\% national sample of Medicare fee-for-service beneficiaries were used to identify three categories of clinicians: (1) "ALF specialists" with $\geq 80 \%$ of their evaluation and management (E\&M) visits in ALFs in a given year; (2) "occasional ALF clinicians" with at least one ALF visit for E\&M, but with these visits totaling $<80 \%$ of their E\&M claims; and (3) "non-ALF clinicians" with no ALF visits for E\&M. Clinicians with $<100$ Part B claims annually were excluded. E\&M visits were identified by Healthcare Common Procedure Coding System codes 99324-99328, 99334-99337 with Place of Service code 13. Other site specialists (e.g., nursing home specialists) have been identified using $90 \%$ thresholds for E\&M claims, ${ }^{3,}{ }^{4}$ but we used $80 \%$ due to the relatively small number of ALF specialists. The IQVIA Physician Database, Medicare Data on Provider Practice and Specialty, and Medicare Accountable Care Organization (ACO) Provider file were used to identify additional characteristics of clinicians.

Received May 6, 2020

Accepted August 14, 2020

Published online September 1, 2020
The proportion of clinicians in each category among all clinicians billing Medicare in each year was examined using the Cochrane-Armitage test for trend. Chi-square tests were used for comparisons of clinician characteristics: age $(\leq 39,40-49,50-59,60-69, \geq 70)$, gender, generalist (internal medicine, family practice, geriatrics, general practice), top 25 medical school graduate, ${ }^{5}$ foreign trained, ACO participant, practice size based on the number of clinicians $(1-9,10-49,50-99, \geq 100)$, employed by an ALF specialized practice ( $\geq 80 \%$ ALF specialists), and rural location.

\section{RESULTS}

The number of ALF specialists increased from 385 in 2014 to 601 in 2017 (56.10\%, $\mathrm{P}_{\text {trend }}<0.001$; Table 1), including an increase in physicians from 98 to 123 (25.51\%) and in APs from 287 to 478 (66.55\%). Occasional ALF clinicians increased from 8990 in 2014 to 11,265 in $2017\left(25.31 \%, \mathrm{P}_{\text {trend }}<0.001\right)$; physicians increased from 5602 to $6088(8.68 \%)$ and APs from 3388 to $5177(52.80 \%)$.

The number of E\&M visits in ALFs by ALF specialists increased $74.53 \%$, from 90,188 in 2014 to 157,402 in 2017 , including increases of $21.81 \%$ for physicians and $98.38 \%$ for APs (Table 1). For occasional ALF clinicians, the number of these claims increased $56.51 \%$, from 223,130 to 291,828 , with increases of $30.79 \%$ for physicians and $98.85 \%$ for APs.

Compared with non-ALF clinicians, ALF specialists and occasional ALF clinicians were more likely to be female $(39.84 \%$ vs $78.27 \%$ and $56.73 \%)$ and in practices of 1 to 9 clinicians (28.21 vs $48.10 \%$ and $41.06 \%$ ), and were less likely to be in rural locations $(10.27 \%$ vs $3.63 \%$ and $9.39 \%$ ) (Table 2). ALF specialists were less likely to be ACO participants compared with occasional ALF clinicians and non-ALF clinicians (14.39\% vs $34.41 \%$ and $33.30 \%$ ) but were more likely to be employed by ALF specialized practices $(17.55 \%$ vs < $0.10 \%$ and $<0.10 \%)$. 
Table 1 Prevalence of Assisted Living Specialists and Occasional Assisted Living Clinicians over the Period 2014 through 2017

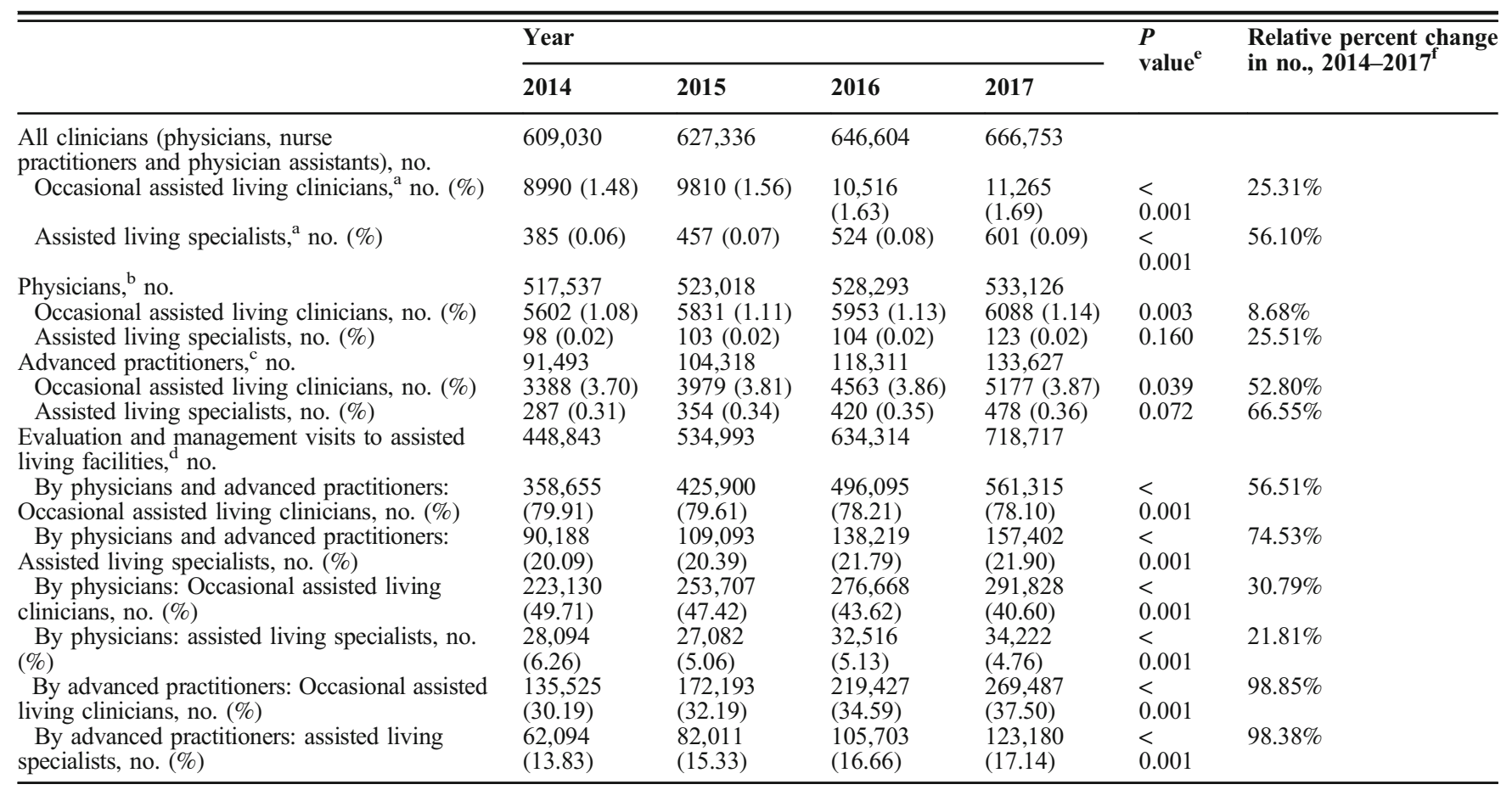

a"Assisted living specialists" defined as physicians and advanced practitioners with at least $80 \%$ of their evaluation and management visits in assisted living facilities in a given year; "occasional assisted living clinicians" were defined as physicians and advanced practitioners having at least one assisted living visit for evaluation and management, but with these visits totaling less than $80 \%$ of their evaluation and management claims. Evaluation and management claims in assisted living facilities were identified by Healthcare Common Procedure Coding System codes 99324-99328 and 9933499337, Place of Service code 13

${ }^{b}$ For physicians who billed for visits in assisted living facilities, the denominator was all physicians billing Medicare Part B claims in that year

${ }^{c}$ For advanced practitioners who billed for visits in assisted living facilities, the denominator was all advanced practitioners billing Medicare Part $B$ claims in that year

${ }^{d}$ For evaluation and management visits to assisted living facilities, the denominator for the percentage was all assisted living billing for evaluation and management in that year

${ }^{e}$ The Cochrane-Armitage test for trend was used to analyze proportion changes over time

${ }^{f}$ The relative percent change was calculated by comparing the number of assisted living clinicians in 2017 to the number in 2014

Compared with physicians who were non-AL clinicians, physicians who were ALF specialists and occasional ALF clinicians were more likely to be generalists $(27.00 \%$ vs $78.67 \%$ and 81.41$)$ and foreign trained ( $24.87 \%$ vs $41.29 \%$ and 36.98$)$, and were less likely to be top 25 medical school graduates $(17.54 \%$ vs $10.17 \%$ and $11.54 \%$ ). On average, physicians were older than APs in each of the three categories.

All comparisons of clinician characteristics were statistically significant at the $5 \%$ level, though the absolute magnitude of some differences was small.

\section{DISCUSSION}

The number of clinicians providing care in ALFs increased rapidly from 2014 to 2017. Growth in E\&M visits in ALFs by APs was far greater than the increase for physicians. ALF specialists provided a disproportionate share of these visits, though the vast majority were provided by occasional ALF clinicians. Future study is warranted to determine whether the number of ALF specialists continues to grow and whether they provide higher quality care than occasional ALF clinicians. 
Table 2 Characteristics of Assisted Living Specialists, Occasional Assisted Living Clinicians, and Non-Assisted Living Clinicians (2014-2017)

\begin{tabular}{|c|c|c|c|c|c|c|c|c|c|}
\hline & \multicolumn{3}{|c|}{ Assisted living specialists ${ }^{\mathrm{a}}$} & \multicolumn{3}{|c|}{$\begin{array}{l}\text { Occasional assisted living } \\
\text { clinicians }^{\mathrm{a}}\end{array}$} & \multicolumn{3}{|c|}{ Non-assisted living clinicians $^{a}$} \\
\hline & All & MD & AP & All & MD & AP & All & MD & AP \\
\hline Total $N$ & 1077 & 225 & 852 & 18,673 & 10,305 & 8368 & 765,885 & 604,767 & 161,118 \\
\hline Generalists $^{\mathrm{b}, \mathrm{c}}$ & NA & $78.67 \%$ & NA & NA & $81.41 \%$ & NA & NA & $27.00 \%$ & NA \\
\hline \multicolumn{10}{|l|}{ Gender $^{\mathrm{b}}$} \\
\hline Female & $78.27 \%$ & $40.44 \%$ & $88.26 \%$ & $56.73 \%$ & $31.33 \%$ & $88.00 \%$ & $39.84 \%$ & $29.27 \%$ & $79.49 \%$ \\
\hline \multicolumn{10}{|l|}{ Age category ${ }^{\mathrm{b}}$} \\
\hline Mean & 48.54 & 55.22 & 46.77 & 50.59 & 53.94 & 46.47 & 49.62 & 51.32 & 43.25 \\
\hline$\leq 39$ & $26.21 \%$ & $9.33 \%$ & $30.67 \%$ & $20.08 \%$ & $11.02 \%$ & $31.24 \%$ & $25.55 \%$ & $20.56 \%$ & $44.28 \%$ \\
\hline$[40-49]$ & $28.81 \%$ & $28.44 \%$ & $28.91 \%$ & $27.72 \%$ & $26.08 \%$ & $29.72 \%$ & $26.55 \%$ & $26.61 \%$ & $26.35 \%$ \\
\hline$[50-59]$ & $23.61 \%$ & $26.22 \%$ & $22.91 \%$ & $27.10 \%$ & $29.52 \%$ & $24.13 \%$ & $23.41 \%$ & $24.75 \%$ & $18.38 \%$ \\
\hline$[60-69]$ & $17.01 \%$ & $20.00 \%$ & $16.22 \%$ & $20.16 \%$ & $25.41 \%$ & $13.70 \%$ & $18.54 \%$ & $20.76 \%$ & $10.23 \%$ \\
\hline$\geq 70$ & $4.37 \%$ & $16.00 \%$ & $1.29 \%$ & $4.94 \%$ & $7.97 \%$ & $1.21 \%$ & $5.94 \%$ & $7.32 \%$ & $0.76 \%$ \\
\hline Attended a top 25 medical school ${ }^{\mathrm{c}, \mathrm{d}, \mathrm{e}}$ & NA & $10.17 \%$ & NA & NA & $11.54 \%$ & NA & NA & $17.54 \%$ & NA \\
\hline Foreign trained ${ }^{\mathrm{c}, \mathrm{d}}$ & NA & $41.29 \%$ & NA & NA & $36.98 \%$ & NA & NA & $24.87 \%$ & NA \\
\hline $\begin{array}{l}\text { Participation in an accountable care } \\
\text { organization }^{\text {f }}\end{array}$ & $14.39 \%$ & $16.00 \%$ & $13.97 \%$ & $34.41 \%$ & $39.97 \%$ & $27.57 \%$ & $33.30 \%$ & $33.92 \%$ & $30.98 \%$ \\
\hline \multicolumn{10}{|l|}{ Practice size $\mathrm{e}^{\mathrm{b}, \mathrm{g}}$} \\
\hline Mean & 77 & 45 & 85 & 147 & 158 & 132 & 306 & 313 & 281 \\
\hline [1-9] & $48.10 \%$ & $66.22 \%$ & $43.31 \%$ & $41.06 \%$ & $46.40 \%$ & $34.48 \%$ & $28.21 \%$ & $30.11 \%$ & $21.07 \%$ \\
\hline$[10-49]$ & $31.57 \%$ & $20.44 \%$ & $34.51 \%$ & $23.41 \%$ & $17.99 \%$ & $30.08 \%$ & $21.01 \%$ & $20.09 \%$ & $24.46 \%$ \\
\hline [50-99] & $8.17 \%$ & $6.22 \%$ & $8.69 \%$ & $9.69 \%$ & $8.23 \%$ & $11.50 \%$ & $9.65 \%$ & $9.18 \%$ & $11.38 \%$ \\
\hline$[100+]$ & $12.16 \%$ & $7.11 \%$ & $13.50 \%$ & $25.84 \%$ & $27.38 \%$ & $23.95 \%$ & $41.13 \%$ & $40.61 \%$ & $43.10 \%$ \\
\hline Employed by an AL specialized practice ${ }^{\mathrm{b}, \mathrm{h}}$ & $17.55 \%$ & $37.78 \%$ & $12.21 \%$ & $<0.10 \%$ & $\begin{array}{l}< \\
0.10 \%\end{array}$ & $<0.10 \%$ & $<0.10 \%$ & $\begin{array}{l}< \\
0.10 \%\end{array}$ & $<0.10 \%$ \\
\hline Rural & $3.63 \%$ & $2.24 \%$ & $4.00 \%$ & $9.39 \%$ & $10.52 \%$ & $7.99 \%$ & $10.27 \%$ & $9.19 \%$ & $14.30 \%$ \\
\hline
\end{tabular}

a"Assisted living specialists" defined as physicians and advanced practitioners with at least $80 \%$ of their evaluation and management visits in assisted living facilities in a given year; "occasional assisted living clinicians" were defined as physicians and advanced practitioners having at least one assisted living visit for evaluation and management, but with these visits totaling less than $80 \%$ of their evaluation and management claims; and "nonassisted living clinicians" were defined as physicians and advanced practitioners with no assisted living visits. Chi-Square tests were used to compare the characteristics of the three clinician groups. All differences were statistically significant at the $5 \%$ level

${ }^{b}$ The Medicare Data on Provider Practice and Specialty file was used to identify generalists (internal medicine, family practice, geriatric medicine, general practice), gender, age, practice size and assisted living specialized practice

${ }^{c}$ The percentages of generalists, attended a top 25 school, and foreign trained were compared for physicians only

${ }^{d}$ The IQVIA Physician Database was used to identify medical schools attended by physicians

${ }^{e}$ Top 25 medical school rankings were drawn from the US News and World Report 2017, America's Best Graduate Schools, Schools of Medicine

${ }^{f}$ The Medicare Shared Savings Program Provider file was used to identify clinicians participating in Accountable Care Organizations

${ }^{g}$ Practice size was defined as the number of unique National Provider Identifiers in the practice

${ }^{h}$ An assisted living specialized practice was defined as a practice that consisted of $80 \%$ or more of assisted living specialists

Mark Aaron Unruh, $\mathrm{PhD}^{1}$

Yuting Qian, $M S^{1}$

Lawrence P. Casalino, $\mathrm{MD}, \mathrm{Ph} \mathrm{D}^{1}$

Paul R. Katz, $M D^{2}$

Kira L. Ryskina, MD, MSHP ${ }^{3}$

Hye-Young Jung, $\mathrm{Ph} \mathrm{D}^{1}$

${ }^{1}$ Weill Cornell Medical College ,

New York, NY, USA

${ }^{2}$ Florida State University College of Medicine,

Tallahassee, FL, USA

${ }^{3}$ University of Pennsylvania Perelman School of Medicine,

Philadelphia, PA, USA

Corresponding Author: Hye-Young Jung, PhD; Weill Cornell Medical College New York, NY, USA (e-mail: arj2005@med.cornell.edu).
Funding Information This study was financially supported by The Physicians Foundation Center for the Study of Physician Practice and Leadership at Weill Cornell Medical College (\#PF 170352-01).

\section{Compliance with Ethical Standards:}

Conflict of Interest: The authors declare that they do not have a conflict of interest.

\section{REFERENCES}

1. Harris-Kojetin LD, Sengupta M, Lendon JP, Rome V, Valverde $\mathbf{R}$, Caffrey C. Long-term care providers and services users in the United States, 2015-2016. 2019.

2. Zimmerman S, Sloane PD, Reed D. Dementia prevalence and care in assisted living. Health Aff 2014;33(4):658-666.

Publisher's Note Springer Nature remains neutral with regard to jurisdictional claims in published maps and institutional affiliations. 